\title{
EL POEMA 167 DE TOMÉ DE BURGUILLOS. PARAVICINO, GUSTAVO ADOLFO DE SUECIA, FELIPE IV Y OTRAS NOTAS
}

En varias ocasiones rinde Lope de Vega tributo de amistad a fray Hortensio Félix Paravicino, a quien cita en una serie de grandes predicadores mencionados en el soneto 38 de las Rimas humanas y divinas del licenciado Tomé de Burguillos, o a cuya empresa alusiva a los riesgos de la envidia dedica otro soneto de Corona trágica, "A una fuente, oprimida de una mano, empresa del Rmo. Pre. Mro. fray Hortensio Félix Paravicino", que empieza "En vano imprimes con la mano impura"; le llama "Hortensio celestial" en La Filomena, y canta su lamento funeral en la égloga Eliso ${ }^{1}$.

En el poema 167 de Burguillos trata un suceso concreto en el que Paravicino se halla involucrado, y que deriva hacia el elogio del rey Felipe IV, ascendido al trono poco antes de la redacción del poema, como intentaré argumentar.

El epígrafe explica las circunstancias de la composición: "Mató su Majestad un venado y mandó llevar parte dél al P. M. Hortensio; y hallándose allí el licenciado Burguillos partió con él y él le envió estos versos".

Hay en este texto algunos pasajes problemáticos que requieren una consideración más demorada de la que hasta la fecha, a mi juicio, se le ha concedido, y que implican cuestiones de puntuación, enmiendas posibles e interpretación general de los motivos citados o aludidos.

El poema, compuesto en liras de seis versos, se dispone en la edición príncipe de $1634^{2}$ individualizando cada estrofa, con sangrado francés y punto final cuando acaba cada lira:

${ }^{1}$ Véase F. Cerdan (ed.), Honras fúnebres y fama póstuma de fray Hortensio Paravicino, Helios, Toulouse, 1994.

${ }^{2}$ Lope De Vega, Rimas humanas y divinas del licenciado Tomé de Burguillos, Imprenta del Reino, Madrid, 1634. 
es un tipo de puntuación y disposición gráfica que atiende a la composición métrica, pero no a la sintaxis ni a la semántica. Lo reproduzco paleográficamente cambiando sólo las eses largas por las normales y manteniendo las varias erratas, algunas señaladas en la fe de erratas de 1634:

Cisne Palauizino,

Pensil Hortensio al estrellado muro

Del Orbe cristalino,

Como su misma inteligencia puro,

Cuyo ignenio ${ }^{3}$ es idea

De quantas formas fabricar dessea.

No menos gracias, quantas

Marauillas de vos la inuidia admira,

Si vestida de tantas

Luzes, Argos la noche el mundo mira,

Con el alma os embio,

Por el fauor de vuestro dueño, y mio.

Sagrada estar deuiera

Al frontispicio de la Diosa Trina,

Esta de aquella fiera

Reliquia, que matò mano diuina,

No como a verla llego,

En Ara humilde de mi pobre fuego.

Aquí solo se via

Nadar la carne en liquido potaje,

Que apenas descubria

Limitada racion de inutil paje,

De misero escudero,

Con berça en Iulio, y nabo por Enero.

Agora quien creyera

Que de tiro Real la muerta caça

El assador vistiera,

Que no la vee por Majestad la pica ${ }^{4}$,

Ni en pintados Sibiles

La ponen Regidores, ni Alguaziles.

El Iouen de Austria, Diuo

Cesar de nuestra Palas siempre armada,

A cuyo rayo viuo

Tiemblan las fieras de la Scitia elada,

3 “ignenio", por errata en la edición príncipe, no señalada en la fe de erratas. Hay que corregir, claro, en "ingenio".

${ }^{4}$ Errata por "plaza", que no se consigna en la fe de erratas de 1634, pero que corrigen todos los editores. Cuando me refiero a la fe de erratas siempre es la de la princeps. 
Que es poco a su decoro,

El Alpe Galo, y el Atlante Moro.

El caçador Apolo

De quien jamas huyera el alma verde,

De aquella por quien solo

Ramas abraça, y paralelos pierde,

Ya que gasta las llamas,

Mate Venados de inuencibles ramas ${ }^{5}$.

El vozo de oro aplique

a la suaue caça, que de Soles

Felipes, multiplique

Con dilatados orbes Españoles ${ }^{6}$,

No en plomo ardiente en fieras ${ }^{7}$,

Que el Tajo le produze en sus riberas.

Verdad es que le mira

El Liuio atentamente, y el Sueco ${ }^{8}$,

Que al de Alemania admira,

De quien nos llega eslabonado el Eco,

Que de vna en otra nueua,

Trayendo fama admiraciones lleua.

Y assi es justo que sepa

Como rige el cauallo, y que vizarro,

Montes fragosos trepa,

Antes que enfrene el Sol los de su carro,

Y como por su lança

Toma del Iauali Venus vengança.

Por el Laurel sagrado,

Que me dio Salamanca en sus Escuelas

Que el caçador soldado,

Puede poner al Hipogrifo espuelas

Y con estos ensayos

Partir despues con Iupiter los rayos.

$\mathrm{Y}$ vos mi amado amigo

Perdonad el retorno, que al cuidado

El alma toda obligo,

Sino es que, irregular mate vn Venado,

Que porque del me acuerde,

Le vi en el Soto de Santiago el Verde.

${ }^{5}$ La fe de erratas manda corregir "invencibles" por "invisibles".

${ }^{6}$ La fe de erratas manda corregir "Con" por "los".

7 La fe de erratas manda corregir "en" por "el” ("en plomo" debe ser "el plomo").

8 La fe de erratas manda corregir "Libio" por "Lirio". 
En las ediciones modernas, que siguen en general criterios de puntuación diferentes a los de 1634, se mantiene en este caso buena parte de la antigua, provocando anacolutos e incoherencias. C, RC y CG, con variantes no relevantes, imprimen ${ }^{9}$ :

Cisne Paravicino ${ }^{10}$, pensil Hortensio al estrellado muro del orbe cristalino, como su misma inteligencia puro, cuyo ingenio es idea

de cuantas formas fabricar desea.

No menos gracias cuantas maravillas de vos la invidia admira, si vestida de tantas luces Argos la noche el mundo mira, con el alma os envío, por el favor de vuestro dueño y mío.

Sagrada estar debiera

al frontispicio de la diosa Trina esta de aquella fiera

reliquia que mató mano divina, no como a verla llego, en ara humilde de mi pobre fuego.

Aquí solo se vía

nadar la carne en líquido potaje,

${ }^{9}$ Manejo para mi comentario las siguientes ediciones de LOPE DE VEGA: Rimas humanas y divinas del licenciado Tomé de Burguillos, ed. J. M. Blecua, en Obras poéticas de Lope, Planeta, Barcelona, 1983; Rimas humanas y divinas del licenciado Tomé de Burguillos, ed. A. Carreño, Almar, Salamanca, 2002; Rimas humanas y divinas del licenciado Tomé de Burguillos, eds. J. M. Rozas y J. Cañas Murillo, Castalia, Madrid, 2005; Rimas humanas y divinas del licenciado Tomé de Burguillos, ed. M. Cuiñas Gómez, Cátedra, Madrid, 2008. Empleo las abreviaturas siguientes: edición de Antonio Carreño (C); Juan Manuel Rozas y Cañas Murillo (RC), y Macarena Cuiñas Gómez (CG). La numeración es la misma en RC y CG; C numera dos poemas preliminares, con lo cual este poema lleva en $\mathrm{C}$ el número 169. Para los efectos de mi interpretación y comentario no son relevantes las diferencias de puntuación que cada editor muestra respecto de los demás, y no las preciso aquí. Reproduzco en este lugar la edición de CG, que es la más reciente. Otras abreviaturas son: Dicc. Aut.: Diccionario de Autoridades, ed. facsímil de la Real Academia Española, Gredos, Madrid, 1990, 3 vols.; Cov.: Sebastián de Covarrubias, Tesoro de la lengua castellana o española, ed. integral e ilustrada de I. Arellano y R. Zafra, Iberoamericana, Madrid, 2006.

${ }^{10}$ CG considera la lectura "Palavicino" de la príncipe errata y enmienda, mal, en "Paravicino" ("En la edición princeps figura el término 'Palavicino" que ha de ser errata por 'Paravicino' y que, por lo tanto, corrijo"). 
que apenas descubría

limitada ración de inútil paje,

de mísero escudero,

con berza en Julio y nabo por Enero.

Agora quien creyera

que de tiro real la muerta caza

el asador vistiera,

que no la ve por majestad la plaza,

ni en pintados sibiles

la ponen regidores ni alguaciles.

El joven de Austria, divo

César de nuestra Palas siempre armada,

a cuyo rayo vivo

tiemblan las fieras de la Scitia helada,

que es poco a su decoro

el Alpe galo y el Atlante moro.

El cazador Apolo,

de quien jamás huyera el alma verde

de aquella por quien solo

ramas abraza y paralelos pierde,

ya que gasta las llamas,

mate venados de invisibles ramas.

El bozo de oro aplique

a la suave caza, que de soles

Felipes multiplique

los dilatados orbes españoles,

no el plomo ardiente en fieras,

que el Tajo le produce en sus riberas.

Verdad es que le mira

el lirio atentamente, y el sueco

que al de Alemania admira,

de quien nos llega eslabonado el eco,

que de una en otra nueva

trayendo fama, admiraciones lleva.

Y así es justo que sepa

cómo rige el caballo y qué bizarro

montes fragosos trepa

antes que enfrene el Sol los de su carro,

y cómo por su lanza

toma del jabalí Venus venganza.

Por el laurel sagrado

que me dio Salamanca en sus escuelas, que el cazador soldado puede poner al hipogrifo espuelas, y con estos ensayos partir después con Júpiter los rayos. 
Y vos, mi amado amigo,

perdonad el retorno, que al cuidado

el alma toda obligo,

si no es que irregular mate un venado,

que porque dél me acuerde,

le vi en el soto de Santiago el Verde.

En el v. 50 mientras CG ha aceptado "el lirio" (según recomendación de la fe de erratas de 1634, que enmienda lo que se imprime en el texto -"Liuio"-), C y RC, en seguimiento de una propuesta de Blecua aceptan "libio" (ya me ocuparé luego de este punto ${ }^{11}$.

Las primeras estrofas presentan menos problemas de puntuación e interpretación.

El v. 1, que inicia un pasaje en vocativo, califica de cisne a Paravicino por su excelencia poética. El cisne es símbolo habitual de los buenos poetas. En la empresa de Paravicino aludida anteriormente (descrita en el soneto lopiano de Corona trágica) un chorro de agua brota de una fuente que tiene forma de cisne, símbolo de la excelsa poesía.

En el "Túmulo al cadáver de Hortensio", Pellicer de Tovar ${ }^{12}$ desarrolla la imagen del cisne para evocar al predicador ("este cisne racional suave, / metáfora no muda de aquella ave, / después del canto alegre suspendido / a un éxtasis con visos de dormido..."), en metáfora usual.

No procede la enmienda propuesta por la más reciente editora del Burguillos, Macarena Cuiñas -que corrige en "Paravicino"-, y por tanto debe mantenerse la lectura de la princeps "Palavicino", que es forma corriente del nombre de fray Hortensio. "Palavicino" trae Nicolás Antonio en su Biblioteca hispana; y lo mismo Anastasio Pantaleón de Ribera en su Fábula de Proserpina, dedicada "al doctísimo y reverendísimo P. M. Fr. Hortensio Félix Palavicino", o Antonio de Solís en el soneto "A la muerte del Rmo. P. Maestro Fr. Hortensio Félix Palavicino"; "Palavicinus" latiniza Juan Interián de Ayala en su Pictor christianus ${ }^{13}$; etc.

11 Ya se han citado otras erratas enmendadas en la fe de erratas. La de "invencibles ramas" por "invisibles ramas" la corrigen C y CG, no RC; "con dilatados orbes" que debe ser "los dilatados orbes" sólo la corrige CG; "en plomo" debe ser "el plomo", sólo corregida por CG.

12 Véase F. Cerdan (ed.), Honras fúnebres..., f. 19v del "Túmulo".

13 Todos los textos en F. CERdan (ed.), Honras fúnebres... 
En el v. 2 la expresión "pensil Hortensio" juega con el nombre del trinitario. Los pensiles ${ }^{14}$ o jardines colgantes -especialmente los de Babilonia- eran famosos desde la antigüedad, y Hortensio (propiamente hortensius sería adjetivo, 'de jardín, de huerto') es un 'huerto o jardín' lleno de flores y frutos de elocuencia. El predicador Juan Rodríguez de León ${ }^{15}$, en su Oración fúnebre a la muerte... de Paravicino lo evoca con la misma metáfora: "Aquel Hortensio o pensil con alma, porque corramos velos al nombre...", y el propio Lope en la égloga Eliso desarrolla imagen parecida ${ }^{16}$, que pone en relación con el motivo de la fuente en el emblema al que me he referido antes:

Hortensio, aquel florido
huerto del cielo, de tan varias plantas
retóricas vestido,
que las humanas y las letras santas
fueron en su labor rosas pangeas,
cultura de sus márgenes hibleas,
el huerto a cuya fuente
puso la mano la villana envidia,
mas su cristal luciente
mientras más le detiene y le fastidia
más fuerzas cobra y por su escura nube
trepa los aires y a los cielos sube...

Interpreto el v. 2 'sirves de pensil, de adorno excelente, al muro estrellado del orbe de cristal' (al cielo) ${ }^{17}$, lo mismo que los pensiles de Babilonia colgaban de los muros de la ciudad. Habría un verbo elidido, "eres", con el valor de 'servir' "con un sujeto, un sustantivo predicado y un dativo", según ha estudiado Dámaso Alonso en la lengua gongorina relacionándolo con los empleos de esse con dativo en latín ${ }^{18}$. Que el muro estrellado sea el cielo no necesita explicación; la imagen se desarrolla en los versos siguientes con implicaciones filosóficas. Merece la

14 "Rigurosamente significa el jardín, que está como suspenso o colgando en el aire, como se dice estaban los que Semíramis formó en Babilonia. Hoy se extiende a significar cualquier jardín delicioso" (Dicc. Aut.).

15 Honras fúnebres, f. 1r de la Oración fúnebre.

${ }_{16}$ Colección de las obras sueltas asi en prosa como en verso, de D. Frey Lope Félix de Vega. IX. Sancha, Madrid, 1777, p. 251.

17 Acabo de citar la égloga Eliso donde Lope llama a Paravicino "huerto del cielo", como exaltación y como alusión a su oratoria sagrada.

18 Véase Dámaso Alonso, La lengua poética de Góngora, S. Aguirre, Madrid, 1935, pp. 158-162, con muchos ejemplos. 
pena subrayar la precisión conceptista de las correspondencias, pues los pensiles de Babilonia colgaban, en efecto, de los muros, como señala Gabriel de Airolo en su Pensil de principes y varones ilustres (1617) cuya dedicatoria al discreto lector bien puede ilustrar el sentido de la metáfora lopiana ${ }^{19}$.

Porque no cause novedad en algunos la propiedad metafórica con que di título de Pensil a mi libro, en su principal significación me pareció declarar la razón que me movió para aplicarlo a la materia y sujeto de que se trata. Plinio en el lib. 19. c. 9. dice que significa el jardín, o huerto edificado en alto, cuyas palabras son: Pensiles corum hortos promouentibus insoles rotis alitoribus, etc. Y Ambrosio en su Dictionario dice: Pensilis hortus qui supra edificia factus est. Fueron por esto celebrados los pensiles de Babilonia, cuya fábrica (sobre sus altos muros) se cuenta por una de las siete maravillas del mundo. De aquí se originó, que (por término de su posición) significase el jardín, o huerto puesto en lugar sublime. Siendo pues la variedad (que se fabrica en este) de cosas supremas (y que la Idea las considera de todo punto elevadas, y casi fuera de la naturaleza) me pareció metáfora propia darle nombre de Pensil, por lo que suspenden, y admiran grandezas de príncipes y hazañas de varones ilustres...

Los vv. 4-6 interpreto: 'eres un pensil tan puro como la inteligencia del cielo (inteligencia divina), cuyo ingenio es la idea de cuantas formas sirven para crear los objetos'. Me parece una ponderación por semejanza, que enaltece la pureza y claridad de la inteligencia de Paravicino por comparación hiperbólica con la misma de la divinidad. Según doctrinas platónicas la inteligencia divina (Demiurgo) produce las ideas que sirven para fabricar las formas, seres u objetos que pueblan el universo. La inteligencia de Paravicino produce sus homilías según su designio. Los términos idea, formas (sinónimos en Platón, con una variación contextual en Lope) denuncian la raigambre platónica de este pasaje.

Mejor sería sustituir el punto que coloca CG al final del v. 6 por el punto y coma de C y RC, o quizá mejor aún dos puntos: después de dirigirse a Paravicino con las hipérboles elogiosas, en esta segunda estrofa aparece el sujeto y verbo principales: "Paravicino... os envío tantas gracias cuantas la invidia admira

19 Véase el texto en la versión electrónica de la Biblioteca Virtual Cervantes: http://www.cervantesvirtual.com servlet/SirveObras /12039417517813728765213/p0000001.htm. 
en vos... para agradecer el favor del rey, dueño vuestro y mío (la carne que os ha enviado y de la que me habéis dado una parte)".

Los envidiosos admiran a su pesar las gracias de Paravicino (vv. 7-8). Este tema de la envidia era muy característico del predicador, y no se menciona de pasada o como mero tópico habitual, sino con toda conciencia, en nueva demostración de las complejidades de estos textos, que juegan con las contingencias de los correlatos. Ya he señalado cómo Paravicino se aplicaba a sí mismo la empresa "Vires ab invidia", que ponía en las ediciones propias con las que obsequiaba a los amigos, como apunta Entrambasaguas ${ }^{20}$. Creo innecesario comentar más demoradamente la dilogía en gracias 'dotes y virtudes que posee Paravicino’ y ‘agradecimientos que envía Burguillos'.

Los vv. 9-10 reciben algunas notas en los editores de estas Rimas. C explica: "La noche cargada de brillantes estrellas se asocia con Argos, un gigante que, según la fábula, tenía cien ojos, dejando siempre abiertos la mitad. Se constituye en símbolo de la vigilancia"; RC: "Argos, cegado por Mercurio, tenía cien ojos"; CG: "Las virtudes que atesora Paravicino y que admira la envidia, se comparan a la cantidad de ojos de Argos que, en cuanto «luces», conforman la noche estrellada que el mundo mira". No veo clara la estructura y sentido de estos versos. La interpretación que me parece mejor sería ésta: 'os envío tantas gracias cuantas en vos admira la envidia, es decir, innumerables gracias; tantas como estrellas viste la noche, os doy tantas gracias como estrellas tiene el cielo'. Tantas corresponde a cuantas, y establece la relación de paridad entre el número de las gracias y las estrellas. La noche, vestida de tantas estrellas, se compara con Argos: 'el mundo mira la noche vestida de tantas luces, convertida en Argos'. La imagen de Argos, el gigante de los cien ojos, para la noche estrellada, no es desconocida en la poesía del Siglo de Oro. Quevedo la usa en su Himno a las estrellas ${ }^{21}$ :

ejército de oro,

que por campañas de zafir marchando, guardáis el trono del eterno coro

${ }^{20}$ J. de Entrambasaguas, "Aportaciones a la bibliografía de Paravicino", en Homenaje al profesor Emilio Alarcos García en el centenario de su nacimiento: 1895-1995, coord. C. Hernández Alonso, Universidad, Valladolid, 1967, p. 227. Véanse unos cuantos casos de portadas con este emblema en F. Cerdan, "Bibliografía de fray Hortensio Paravicino", Criticón, 8 (1979), 1-149.

${ }^{21}$ Francisco de Quevedo, Un Heráclito cristiano, eds. I. Arellano y L. Schwartz, Crítica, Barcelona, 1998, núm. 102. 
con diversas escuadras militando;

Argos divino de cristal y fuego,

por cuyos ojos vela el mundo ciego (vv. 7-12).

La siguiente estrofa se centra en la pieza de carne recibida como regalo, utilizando un lenguaje religioso: 'la carne es reliquia sagrada del venado que mató la mano divina del rey, y debería colocarse en el templo de la diosa de la caza, Diana, no en el fogón de Burguillos, ara ${ }^{22}$ demasiado humilde para este sacrificio'. La elevación léxica y la complejidad sintáctica, con hipérbatos y quiasmos, además de las alusiones cultas, contrasta con la siguiente lira de tono más costumbrista y doméstico. El frontispicio lo interpreta C como 'cara de Diana' y CG como 'templo', que me parece la mejor acepción en el contexto. Recuérdese que era costumbre de los cazadores antiguos colgar los trofeos de caza en los árboles y peñas en honor de Diana, como evoca Góngora en la Soledad I, y comenta Pellicer, que cita entre otros muchos un pasaje de Tito Livio donde se habla de los cuernos colocados en el vestíbulo del templo de Diana ${ }^{23}$ :

Toca don Luis la ceremonia antigua de los cazadores, que colgaban en los árboles las cabezas de las fieras que fenecían a sus manos. Claramente lo da a entender el escoliasta de Aristófanes in Pluto, así: Consuetudo fuit venatoribus partem predae, caput aut pedem clavo affigere ex quapiam arbore in silva ipsa, in honorem Dianae... Tito Liviio, 1. 1, Fixa per multas aetates cornua in vestibulo templi Dianae... Don Luis dice que se cuelgan en los árboles porque en el siglo más anciano los dioses falsos tenían sus templos en los árboles...

La diosa trina es Diana/la Luna, porque tiene tres personificaciones y tres caras. Escribe Covarrubias:

Luna. El planeta más inferior del cielo de los siete, latine luna, a lucendo, dicha en la Escritura luminare minus, en respeto del sol, que se llama luminare maius. El medio cuerpo de la luna está siempre alumbrado del sol; pero en razón de apartarse o alejarse dél, causa en la tierra diferentes formas y apariencias. Y así unas veces nos parece un broquel de fuego, otra una rebanada de melón o un medio círculo, y cuando es luna nueva, un arco muy delgado. Con estas diferencias fingen los poetas tener tres rostros, como

22 "Ara. Es el altar para hacer sacrificio a Dios" (Cov.).

23 José Pellicer, Lecciones solemnes a las obras de don Luis de Góngora, facsímil, Georg Olms, Hildesheim, 1971, cols. 357-358. 
dijo Virgilio, 4, Aeneidos: “Tria virginis ora Dianae". Llamáronla con tres nombres: Luna en el cielo, Diana en la tierra y Proserpina en el Infierno. Lo demás se remite a los poetas, y podrás ver a Natalis Comes, que lo trae todo.

Así la invoca don Quijote al pedirle nuevas de su Dulcinea: "Dame tú nuevas della, joh luminaria de las tres caras!" (Quijo$t e, \mathrm{I}, 43)$.

Nada especial que comentar requieren los vv. 19-24, pero la puntuación reclama más precisiones en los vv. 25-30, donde sería mejor puntuar como pregunta retórica, ya que plantea una admiración al contraponer la magra comida habitual del licenciado con la ración de carne recibida de la caza del rey ("Aquí", es decir 'en mi casa' -la de Burguillos- 'solo se veía un potaje líquido con un poco de carne, comida de paje o escudero muertos de hambre, con algo de berza y nabos según la estación' y "Agora ¿quién creyera...?", etc.)

Pero lo que más llama la atención es la estrofa de los vv. 31-36, cuyo sujeto ("El joven de Austria"), según la puntuación de los editores, carece de verbo.

La estrofa siguiente constituye un paralelo con ésta ("El joven de Austria"/"El cazador Apolo") y en el v. 42 aparece el verbo "mate", que se refiere tanto a "el joven de Austria" como a "el cazador Apolo" (dos perífrasis referidas igualmente al rey). Propongo puntuar, por tanto:

El joven de Austria, divo

César de nuestra Palas siempre armada, a cuyo rayo vivo tiemblan las fieras de la Scitia helada, -que es poco a su decoro el Alpe galo y el Atlante moro-, el cazador Apolo, de quien jamás huyera el alma verde de aquella por quien solo ramas abraza y paralelos pierde, ya que gasta las llamas mate venados de invisibles ramas.

La interpretación de estos versos tampoco es evidente en todos sus detalles. Entiendo el conjunto de los vv. 31 ss.: 'El joven de Austria, a cuyo valor (simbolizado por el rayo) tiemblan las terribles fieras de la Scitia - pues es poco que ante él tiemblen 
los franceses y los moros-, el Apolo cazador (el rey), este Apolo de quien no hubiera huido Dafne (como huyó del Apolo mitológico) ya que gasta el tiro de su arma, en vez de venados de cuernos visibles (animales) en la caza, mate mejor venados de ramas o cuernos invisibles, es decir, venados sin cuernos (hombres enemigos) en la guerra. Pero será mejor que aplique el bozo de oro ${ }^{24}$, es decir, aplique su actividad, a otro tipo de caza, la amorosa (suave caza), que engendre numerosos sucesores (multiplique los orbes españoles de Felipes -sus hijos-) y no gaste el plomo de las balas en la caza de fieras. Aunque por otro lado es verdad que el francés vigila atentamente el poderío español, y también lo vigila atentamente el sueco (el rey Gustavo Adolfo) que tiene atemorizado al Imperio (admira al de Alemania: asusta al emperador) con sus hazañas cuya fama llega hasta España: por eso está bien, a fin de cuentas, que el rey se ejercite en la caza, para que sus enemigos sepan que tiene capacidades guerreras'.

Convendrá justificar brevemente algunas de estas interpretaciones ${ }^{25}$ que intentan seguir el razonamiento un tanto sinuoso del poema.

RC apuntan que estas liras son anteriores a diciembre de 1633, fecha de la muerte de Paravicino. Felipe IV nace en 1605 y sube al trono en 1621: en el poema es ya rey, de modo que la composición será posterior a 1621; se le llama "joven de Austria" y si el bozo del v. 43 (en propia interpretación de RC) es el primer vello que nace al joven sobre el labio superior (Dicc. Aut.), y se le incita al ejercicio de la caza y a campañas militares futuras, probablemente corresponda a los primeros momentos del reinado de Felipe IV.

Se le augura una larga descendencia: no parece haber nacido aún Baltasar Carlos (17 de octubre de 1629) ${ }^{26}$. La primera hija de Felipe IV, María Margarita nace en agosto de 1621 y las siguientes hijas del rey en 1623 (Margarita María, muerta con un mes), 1625, 1627... Evidentemente las hijas no son "Felipes": el poema puede haber sido escrito después del nacimiento de

${ }^{24}$ Aquí se abren dos posibilidades de interpretación de bozo: bien el primer vello sobre el labio superior, referido a la juventud del rey; bien la rienda del caballo, referido a su actividad cazadora.

${ }^{25}$ En general, los editores explican los significados literales de algunos vocablos como sibiles o decoro, y dan noticia de Dafne y otras fábulas mitológicas aludidas, pero no se ocupan del sentido contextual.

${ }^{26}$ Si hubiera nacido sería impropio desearle una larga serie de "Felipes", habida cuenta del nombre que se le puso al príncipe. 
alguna de las princesas, pero si el poema se escribe cuando el rey aún no ha tenido descendencia ninguna, sería del mismo año de 1621, o en todo caso entre 1621 y 1629. Una vez nacido Baltasar Carlos no tendría sentido augurar "muchos Felipes": por lo demás en esa fecha Felipe IV lleva ocho años gobernando, y no parece adecuado calificarlo a esas alturas de "joven de Austria" todavía en el comienzo de su tarea. Estas liras deben de ser cercanas a 1621.

El uso de "divo" (término aplicado a los emperadores romanos) se corresponde al calificativo de "César", estableciendo una agudeza de proporción.

La Palas armada (diosa de la guerra) ${ }^{27}$ debe de representar a la monarquía española, a España, de quien es César Felipe IV. Es simbolismo conocido que recoge, por ejemplo, Sebastián de Covarrubias Horozco en sus Emblemas morales (Luis Sánchez, Madrid, 1610), centuria 3, emblema 12, donde Palas Atenea sostiene un escudo con las armas de Castilla y León, y expresa la belicosidad extraordinaria que se atribuía tópicamente a los españoles ${ }^{28}$ :

...tales son nuestros españoles, generosos, y valientes, que en cuanto tratan unos con otros en su tierra, el más bravo es más cortés, reportado, y sufrido, pero saliendo a la guerra (sin agravio de nadie) la nación española es más arriscada y valerosa de cuantas hay en el orbe.

Las fieras de Scitia (región del Asia antigua) como ejemplo de crueldad y lo indomable de sus habitantes era imagen tópica. El epíteto de helada es igualmente habitual: Scitia se caracteriza por sus fríos eternos en los textos del Siglo de Oro. La fiereza y el frío de Scitia los reúne el mismo Lope en otro poema de las Rimas, soneto "Amor, no pienses que te pintan tierno": "que no hay Scitia cruel como tu invierno", y otros textos. Véase también el Viaje del Parnaso de Cervantes, comentario de Herrero a los vv. 199-200 del capítulo 6, "Desde la ardiente Libia hasta la

27 En esta condición se la representa con armadura y égida.

28 Baste remitir a Quevedo, España defendida, cap. 5: "sin duda ha ejercitado más las armas y la virtud militar que las demás naciones... Todos los antiguos escritores nombraron a los españoles entre las naciones más belicosas" (Obras completas. Prosa, ed. F. Buendía, Aguilar, Madrid, 1974, pp. 585, 586). 
helada / Citia” ${ }^{29}$, donde se recuerda un texto de Vasco Díaz Tanco que precisa su situación ("Esta región de Scitia confina de la una parte con el reino de Tartaria y de otra con el mar Caspio o Hircano"), y otro de Villegas: "Vete, vete a la Citia / donde continuamente / se hielan hondos ríos, / se cuajan altas nieves".

Estas fieras habitantes de la Scitia tiemblan del rayo de Felipe IV (nótese la ingeniosa contraposición del hielo y el fuego del rayo), para quien es poco hacer temblar a los enemigos y rivales, simbolizados en dos montañas: el Alpe para los franceses (parece una licencia poética de metonimia para 'Pirineos') y el Atlas para los $\operatorname{moros}^{30}$.

La comparación de Felipe IV con Apolo implica muchos requisitos de agudeza, como dijera Gracián, aun siendo en sí misma fácil de entender: Apolo es el dios arquero, cazador, y es el dios del sol. Felipe IV se identifica con el sol (símbolo tópico) con mayor razón que otros monarcas, ya que al ser el cuarto Austria corresponde emparejarlo con el cuarto planeta del sistema de Tolomeo (sol), y en las circunstancias de la caza se establece una agudeza de proporción entre la identificación con Apolo (dios cazador) y la práctica de la caza.

La semejanza se prosigue con una agudeza hiperbólica de contrariedad condicional que se suma a la paridad anterior -modo excelso de agudeza este de juntar en una misma expresión contrariedad y paridad-: mientras que Dafne huyó del Apolo mitológico ${ }^{31}$ jamás hubiera huido de este otro Apolo español, superior al dios.

29 Miguel de Cervantes, Viaje del Parnaso, ed. M. Herrero, CSIC, Madrid, 1983, p. 773.

30 "Atlas. Fue rey de Mauritania; fingen los poetas haber sustentado sobre sus hombros el cielo, para significar el mucho conocimiento que tuvo del curso del sol, luna y estrellas; fingen también que Prometeo, su hermano, le pronosticó que se guardase de un hijo de Júpiter, de quien había de recibir gran daño, si le admitiese por huésped; éste fue Perseo, que mostrándole la cabeza de la Gorgona le convirtió en monte; todo ello tiene su moralidad, y podrás ver a Natal Comité" (Cov.). Natal Conti explica: "Y que el monte Atlas es el más alto lo atestigua así Heródoto en Melpómene (IV, 184): Cerca de esta sal hay un monte cuyo nombre es Atlas, es estrecho y totalmente circular y tan elevado que se dice que sus cumbres no pueden verse, pues nunca las abandonan las nubes ni en verano ni en invierno. Los habitantes dicen que éste es la columna del cielo" (Mitología, trad., introd. y notas de R. M. Iglesias y M. C. Álvarez, Universidad, Murcia, 1988, p. 252).

31 Ese Apolo-Sol, enamorado de Dafne, abraza ramas cuando la ninfa se transforma en laurel, y pierde los paralelos ('líneas en la esfera celeste'), porque abandona el cielo para perseguir a Dafne. 
El verbo "mate" del v. 42 se refiere al sujeto gramatical doble "El joven de Austria... el cazador Apolo". Lo que ha de matar son venados de ramas invisibles, venados sin cuernos ('hombres enemigos'), como ya he apuntado.

En el v. 43 el bozo plantea alguna dificultad: el contexto de "suave caza" que multiplique de "soles Felipes" los orbes españoles parece apuntar con pocas dudas a la feliz descendencia de la estirpe. Esta caza suave (las tareas generativas, matrimoniales, se entiende) se contrapone a la caza que consiste en matar fieras con el plomo ardiente de los arcabuces. Si bozo es, como piensan RC, el primer vello que apunta a los jóvenes, sería referencia metonímica a la juventud del rey 'aplica tu juventud a engendrar gloriosa estirpe de reyes'32; si es, como piensa CG, "cuerda que se echa a las cabalgaduras sobre la boca", sería metonimia de la actividad cinegética 'aplica tus fatigas a otra caza más suave'.

La errata del v. 50 provoca en los editores soluciones diversas. Lo que imprime la príncipe es "Liuio" y la fe de erratas pide corregir en "Lirio". Es evidente que la fe de erratas no tiene en este caso ella misma errata, como parecen pensar Blecua y RC, quienes proponen la lectura "libio", ya que no ven ningún sentido a "lirio"33.

Pero téngase en cuenta que en las prácticas ortográficas del Siglo de Oro no habría diferencia entre "liuio" y "libio" (no habría diferencia entre livio/liuio/libio) por lo cual sería incomprensible en una fe de erratas corregir "liuio" por "libio", que sería lo mismo; para un corrector del Siglo de Oro no es posible considerar errata un cambio del tipo livio por libio. De hecho, significativamente, la fe de erratas de 1634 no pide corregir "livio" por "lirio", como escriben RC, sino que pide corregir "Libio, di. Lirio" ${ }^{44}$. Y "lirio" es lo que hay que leer.

Esta estrofa de los vv. 49-54 corresponde al ámbito europeo de los rivales de España en este momento: el rey de Francia (el lirio, la flor de lis, flor heráldica de la realeza francesa ${ }^{35}$ mira

32 Bozo de oro: por su color rubio (Felipe IV era sobre todo de joven bastante rubio) y su condición solar; y si es ramal para el caballo por la riqueza de su material.

${ }^{33}$ Curiosamente los anotadores dan el buen sentido: no tendría sentido la lectura lirio, dicen "a no ser que aluda al rey de Francia”, lectura buena que acaban rechazando con poca razón.

34 "Libio" con $b$ en la fe de erratas, pero en el poema lo que aparece es "Liuio".

35 Comp. el título del auto de Calderón El lirio y la azucena, sobre la paz de los Pirineos, o la expresión francos lirios, perífrasis metonímica por 
atentamente para ver qué hace el rey de España. Y también lo mira el sueco, otro monarca que aspira a la hegemonía, para quien España es enemigo capital, como se mostrará en la Guerra de los Treinta Años.

El verbo "admira" lleva por sujeto "el sueco" y por objeto indirecto "al alemán”: 'el sueco admira al alemán’36. Hay que precisar que el significado de admirar no es aquí 'considerar algo o alguien con estima y respeto extraordinario' (el sueco no respeta y estima al alemán) sino 'causar admiración, con el matiz de miedo y asombro, provocar temor' (el sueco asusta al alemán, al Imperio) ${ }^{37}$.

Algunos de estos motivos se aclaran yendo, por ejemplo, al soneto 36 de Burguillos "A la muerte de rey de Suecia" (caído en la batalla de Lützen, 16 de noviembre de 1632), donde se subraya la amenaza que supone para el Imperio el rey Gustavo Adolfo II (que había subido al trono en 1611) y que en 1621 había conquistado el importante enclave comercial de Riga:

El sucesor del gótico arrogante
que fulminó dos veces Carlos Quinto,
en blanco armado, aunque de sangre tinto,
del Sacro Imperio presumiose Atlante.
Estaba el mundo en acto circunstante,
si bien el voto universal distinto,
cuando cayó de tanto laberinto
con breve plomo el ínclito gigante.
Mesurose el león de España, el ave
del imperio paró las sacras plumas
y el gran Melquisedec doró la llave.
Que suelen de olas infinitas sumas,
pensando, altivas, contrastar la nave,
nacer montañas y morir espumas.

Este rey sueco, "del Sacro imperio presumiose Atlante" no por defensor del Imperio (como anota GC en el poema 36) sino

\footnotetext{
'franceses' en El amor médico de Tirso, ed. B. Oteiza, Instituto de Estudios Tirsianos, Madrid-Pamplona, 1997, v. 3606.

36 No significa que el francés y el sueco admiren al alemán (CG: "lirio y sueco: habitantes lejanos [«lirio» alude al rey de Francia] que admiran al alemán”). La concordancia está en singular, y afecta sólo al alemán "al de Alemania admira".

37 "Admirar. Causar y producir admiración en algún sujeto, lo cual no sólo se dice de las personas, sino de los objetos, como El templo de San Pedro admira a cuantos le ven" (Dicc. Aut.). Pues bien, el sueco admira al de Alemania.
} 
porque pretende usurparlo. Nada de extraño tiene que el alemán (el emperador) esté admirado y preocupado.

No sólo el alemán: los ecos de las hazañas del rey nórdico llegan hasta España: "nos llega eslabonado el eco / que de una en otra nueva / trayendo fama admiraciones lleva". Añadiré algunos datos sobre la consideración de Gustavo Adolfo en la poesía del Siglo de Oro español y la impresión que su figura causaba en la época.

Quevedo, por ejemplo, lo llama en el poema de la "Jura del príncipe" 38 "monstruo de Stocolmia" (estrofa 24) y le contrapone a Felipe IV en imagen de Júpiter, la misma que trae Lope en el Burguillos:

Tal osa contra ti, tal le contemplo

al monstro de Stocolmia, que tirano padecerá castigo cuando templo se prometió sacrílego y profano; tú a Flegra añadirás ardiente ejemplo; allí triunfante colgará tu mano su piel de alguna planta, que cargada a fuerza de soberbia esté humillada (vv. 185-192).

Se aprecia cómo el rey Felipe IV se ha convertido en Júpiter que derrotará en una nueva Flegra a los temidos gigantes/suecos, a los que se presenta individualizados por su rey. Las implicaciones ideológicas no pueden ser más claras: los herejes son los gigantes que pretenden usurpar el puesto del auténtico rey y de la verdadera religión.

Quevedo dedica al mismo rey el soneto "Rayo ardiente del mar helado y frío" ${ }^{39}$ que lleva por título "Lamentable inscripción para el túmulo del rey de Suecia Gustavo Adolfo" en la igual ocasión que provoca el soneto 36 de Lope:

Rayo ardiente del mar helado y frío, y fulminante aborto, tendí el vuelo; incendio primogénito del hielo, logré las amenazas de mi brío.

Fatigué de Alemania el grande río; crecile, y calenté con sangre el suelo;

38 Véase Francisco de Quevedo, La musa Clío, eds. I. Arellano y V. Roncero, EUNSA, Pamplona, 2001, p. 156.

39 Francisco de Quevedo, Poesía original, ed. J. M. Blecua, Planeta, Barcelona, 1981, núm. 262. 

azote permitido fui del cielo
y terror del augusto señorío.
Y bala providente y vengadora,
burlando de mi arnés, defensa vana,
me trujo negro sueño y postrer hora.
$\mathrm{Y}$, despojo a venganza soberana
alma y cuerpo me llora quien me llora:
el que los pierde, ¿qué victorias gana?

Vigilado por tales rivales es justo y conveniente que el sueco y el francés sepan cómo gobierna el caballo y qué montes trepa el rey de España (sepan qué habilidades y valor posee). Con el ejercicio de la caza el rey ensaya para la guerra: sus rayos serán tan fulminantes como los de Júpiter, imagen usual para Felipe IV, que ya se ha ejemplificado en el texto quevediano. Es capaz de gobernar el hipogrifo, "animal fabuloso que fingen tener alas y ser la mitad caballo y la mitad grifo... Tómanle los poetas por caballo veloz" (Dicc. Aut.). En el Orlando furioso de Ariosto es montado por Astolfo. Véase Calderón, los primeros versos de La vida es sueño: "Hipogrifo violento, / que corriste parejas con el viento".

En la última estrofa hay otro lugar difícil: Burguillos se excusa por no poder devolver el favor a Paravicino, que le ha regalado parte de la caza del rey, a menos que mate un venado que ha visto en el soto de Santiago el Verde.

Todos los editores anotan la romería de Santiago el Verde (1 de mayo) en el Soto de Manzanares, pero ninguno el adjetivo de "irregular" ni el sentido de la lira. A mi juicio es una alusión, quizá personal, a un personaje satirizado (quizá un clérigo): 'Perdonad, Paravicino, que no os devuelva la atención de haberme invitado a comer del venado que os regaló el rey; pero os lo agradezco con toda el alma; a menos que (es una posibilidad) pueda devolveros la atención si mato un venado que vi en el soto en la romería de Santiago el Verde, metafórica y burlescamente, un cornudo (incurriendo al matarlo en irregularidad)'.

No se me alcanza la presencia de este adjetivo irregular salvo que se use jocosamente en el sentido técnico eclesiástico, como lo aplica Quevedo en un soneto contra la superstición de los cometas (Poesía original, núm. 525):

A venir el cometa por coronas ni clérigo ni fraile nos dejara, y el tal cometa irregular quedara en el ovillo de las cinco zonas. 
Covarrubias define la irregularidad:

Irregularidad. El Presidente, mi señor, don Diego de Covarrubias, en la Clementina Si furiosus, de homicidio, en el principio dice estas palabras, dando la definición de irregularidad: "Irregularitas est canonicum impedimentum, ex facto seu defectu proveniens, quo quis prohibitur ad ecclesiasticos ordines promoveri et eisdem ministrare". No tengo qué entremeterme a más de lo dicho. El que incurre en esto con culpa, y algunas veces sin ella, se llama irregular.

O como define irregular el Dicc. Aut.: "se toma asimismo por el que ha incurrido en irregularidad y por eso está incapaz de los oficios y ministerios eclesiásticos"; irregularidad es "impedimento canónico para recibir órdenes o ejercitar los recibidos o adquirir lo que se provee de derecho eclesiástico, que los sagrados cánones imponen por razón de ciertos defectos u delitos" (Dicc. Aut.).

Cometer un homicidio en ciertas condiciones era una importante causa de irregularidad. Si matando un venado de la romería de Santiago el Verde queda irregular será porque ese venado es metáfora alusiva a un cornudo, y quizá específicamente a un clérigo (atacar y especialmente matar a un clérigo era causa de grave irregularidad). Quizá es un chiste sin más, quizá una alusión a algún personaje mal visto por Paravicino y/o Lope, cuya identificación se me escapa.

Otra posibilidad, menos ingeniosa y más trivial, podría sugerirse, si el locutor incurriera en irregularidad por el mero hecho de practicar la caza. La afición de muchos clérigos a la caza es motivo literario muy frecuente, pero en muchas constituciones sinodales se recuerda la prohibición de este ejercicio, y se considera motivo de irregularidad en algunos casos: esta circunstancia no afectaría al locutor Burguillos, pero sí podría aplicarse a Lope de Vega, ordenado sacerdote ya en 1614. No me parece muy aceptable esta opción: las referencias a la romería de Santiago el Verde, y la casualidad de haber visto al tal venado "para que dél me acuerde" parece sugerir el sentido malicioso, tenga el chiste un referente real o sea simplemente un juego.

Estos 72 versos enviados a Paravicino pueden, en suma, ejemplificar significativamente el tipo de varia y compleja literatura conceptista del Burguillos, que integra elementos domésticos y 
costumbristas propios de la poesía jocosa, con referencias históricas y panegíricos cortesanos, y otras alusiones mitológicas y culturales, en una mezcla unificada por el ingenio admirable de su autor.

IgNAGio Arellano GRISO-Universidad de Navarra 